\title{
Facilitation and groupwork tasks in self-directed groupwork
}

\author{
Jennie Fleming ${ }^{1}$ and Dave Ward ${ }^{2}$
}

\begin{abstract}
In this paper we will briefly set out the principles and process of the selfdirected groupwork model but our main focus will be on how people are putting the model into practice and changes we have observed in relation to groupwork tasks and facilitation within its application over the past 3 decades. Whilst we have found that self-directed groupwork continues to be practised by a range of professionals it is equally used by self-run groups with no input from a professional worker.
\end{abstract}

Keywords: self directed groupwork; group work; empowerment; service user led process

1. Reader in Participatory Research and Social Action and Director Centre for Social Action, De Montfort University, UK

2. Professor of Social and Community Studies, De Montfort University, UK

Address for correspondence: Both authors can be contacted at info@socialactionnet.com

Acknowledgements: The authors wish to acknowledge the major contribution that has been made to their thinking by discussions with innovative group facilitators who have shared their knowledge and experiences with us and so have contributed to the application and development of the Social Action/self-directed groupwork model.

People who specifically contributed material to this paper are: Miriam Harris, Dominique Davis, Keyani Kenny, Aniya Hodges and Chris Lawton of Youth Dreamers; Julie Gosling of Advacacy in Action; Larry Gardiner of Family Advocacy Network and Joan Arches UMASS; Harrison Carter of the campaign against mosquito devices.

Date of first (online) publication: 
Facilitation and groupwork tasks in self-directed groupwork

\section{Introduction}

Self-directed groupwork was formally constructed by Mullender and Ward in 1991, in Self-directed Groupwork: Users take action for empowerment. At the start of their book they wrote that the model had 'grown directly out of the efforts of many groupworkers and group members to find a way of working together that is rooted in anti-oppressive principles'. They recognised the centrality of the work of practitioners in pushing out the boundaries of groupwork and contributing to the development of the self-directed groupwork model. This is no less true for Empowerment in Action: Self-directed groupwork (Mullender, Ward, \& Fleming, 2013) where the self-directed groupwork model is revisited and refined for current and future groupwork practice, in which we continued to draw heavily on the generosity of groupworkers and group members to tell us their stories and share their wisdom about groupwork.

The development of self-directed groupwork has always drawn strongly on people who have shared with us their knowledge of selfdirected groupwork; they have given deep and rich insights to the reality of groupwork and most importantly have enriched our thinking and knowledge about self-directed groupwork and how it is being put into practice. In the same manner as Whitmore et al (2011) express, we have attempted to connect and relate 'individual ideas, thoughts and groups coming together to create a story reflecting the richness and complexity' of what groupworkers and, in many instances, group members told us (Whitmore et al, 2011, p.19). This paper draws on a body of information specially collected by the authors about people's understanding and use of self-directed groupwork.

\section{Self-directed groupwork}

Self-directed groupwork and, alongside it, Social Action, (which is a specific theory and practice for social change that uses self-directed groupwork as a strong element (Fleming, 2009) are continually developing as a way of working. These changes take place within the framework of values, principles and processes that evolve over time and change in detail but are non-negotiable in terms of an over-arching view of the world.

A notable feature of the self-directed approach is its clear and explicit

Groupwork Vol. 23(2), 2013, pp.xx-xx. DOI: 10.1921/4901230203 
value-base which is outlined in the form of six practice principles emphasising: the avoidance of labels, the rights of group members, basing intervention on a power analysis, assisting people to attain collective power through coming together in groups, challenging oppression though practice, and groups being facilitated rather than led. The most current version of these principles is set out below:

1. We are committed to social justice. We strive to challenge inequality and oppression in relation to race, gender, sexuality, age, religion, class, disability or any other form of social differentiation.

2. We believe all people have skills, experience and understanding that they can draw on to tackle the problems they face. We understand that people are experts in their own lives and we use this as a starting point for our work.

3. All people have rights, including the right to be heard, the right to define the issues facing them and the right to take action on their own behalf. People also have the right to define themselves and not have negative labels imposed upon them.

4. Injustice and oppression are complex issues rooted in social policy, the environment and the economy. We understand people may experience problems as individuals but these difficulties can be translated into common concerns.

5. We understand that people working collectively can be powerful. People who lack the power and influence to challenge injustice and oppression as individuals can gain it through working with other people in a similar position.

6. We are not leaders, but facilitators. Our job is to enable people to make decisions for themselves and take ownership of whatever outcome ensues. Everybody's contribution to this process is equally valued and it is vital that our job is not accorded privilege.

(Mullender, Ward, Fleming, 2013, p. 49).

Self-directed groupwork combines two essential and inseparable elements: these six practice principles and a specific process. They are interdependent; the principles elevate the process beyond a set of techniques that, otherwise, would be barely distinguishable from other practices. Conversely, the principles without the process are unlikely to foster action or change. The approach enables groups of all ages and 
circumstances to take action and to achieve their collective goals. It offers an easy-to-understand and open-ended process that makes it possible for people to identify and act on issues that are important to them, while working within a set of values. The process involves starting with groups considering and describing what is going on in their lives collectively and identifying areas for change; they then consider why these issues exist. Next the group thinks of how participants might be able to take action to change things (a planning stage). They then undertake an agreed and planned course of action, following which the group together reflects on what has gone well, what has not, why and how things could be done differently to move further towards their goal. As this description indicates, it is an iterative and cyclical process. Self-directed groupworkers provide the framework for groups to consider problems, issues and concerns. Group members provide the content, using their skills, knowledge and expertise. Group members create the knowledge and understanding through active participation: describing, suggesting, analysing, deciding, experiencing and reflecting (Fleming and Ward, 1999).

Inherent in the six principles is an assumption of a social structural analysis of the issues facing marginalised groups. Self-directed groups do not have therapeutic purposes. All the groups that have helped develop our understanding of self-directed groupwork are groups that are not primarily about meeting individual needs of the participants - though this may of course happen and beneficial intrapersonal and interpersonal outcomes may come about as a result of participation in self-directed groups. Rather the focus is on addressing a shared 'external' issue (Munford and Walsh-Taipati, 2001, p.70).

Having said that, self-directed groupwork is grounded in a great many generic skills, as identified, for example, in the Standards for Social Work with Groups (Abels and Garvin, 2010) and shared in application with critical and structural approaches to social work (e.g. Mullaly, 2010). Indeed, Cohen and Mullender (2000) have pointed out that members of self-directed groups may actually achieve a greater degree of individual change than members of deliberately therapeutic groups, simply because of the benefits of getting involved and of coming to believe in themselves through what they are doing. Certainly, given that self-directed groupwork is grounded in generic groupwork skills, it is perhaps not surprising, therefore, to see progress on several fronts 
in well-run groups. Mullender and Ward $(1985,1991)$ have always seen the individual change achieved in self-directed groups as a 'secondary advantage' and it remains the fact that it is the external change goals that predominate. Self-directed groupwork starts with the external and focuses there, celebrating the 'secondary advantage' of individual growth and change.

Over the years there have been a number of articles in Groupwork exploring the theory and practice of self-directed groupwork and Social Action, for example Ward and Mullender (1991); Harrison and Ward (1999); Fleming and Luczynski (1999); Aubrey (2004); Cary et al (2004) and most recently Arches (2012).

\section{The groups}

We recently undertook some research to find out how relevant people thought self-directed groupwork was to them, what self-directed groupwork was taking place currently and whether people were working in ways that related to the model. We found ourselves having conversations with people in the UK, Ireland, France, USA, Canada and New Zealand. We found a wealth of groupwork happening, both based in and arising directly from self-directed groupwork or Social Action approaches. We drew also from many people who, when we described the process and principles of the model, immediately responded with 'that is just what we do' or said that they could easily recognise the model in what they were doing.

In the course of our research we found self-directed groups in a wide range of settings, for example in schools and in a variety of independent movements outside the predominating contexts of health and social care. Thus, we found groups in the UK, for example, developing community support for older and disabled people and self-advocacy groups of people with dementia; groups of mental health service users in France and Canada; a range of groups supported by professional workers for family support in the UK, New Zealand and Canada. We came across projects of refugees and immigrants and a university lecturer in the US using self-directed groupwork as both method and subject in a Service Learning programme, with the students then taking self-directed groupwork to groups of young people in the community 
(Arches, 2012). There are young people in Baltimore, USA, who have worked hard over many years, facilitated by a high school teacher, to achieve their own community-based youth-run centre (Berdan et al, 2006; Carey et al, 2004) and, in the UK, young people using a selfdirected groupwork approach to organise campaigns against 'mosquito' devices set up to keep them out of public spaces (BBC, 2011). We met young people who had formed Asian Pride a self-directed group for lesbian, gay, bisexual and transgender Asian and Pacific Islanders in the US (http://www.asianprideproject.org/). We even found that some groups such as Advocacy in Action and Turning Point, who had contributed to Mullender and Ward (1991), were still active.

Self-directed groupwork has elements in common with participatory research groups and action research (McIntyre, 2008). Indeed selfdirected groupwork has informed the development of Social Action research, where researchers drawing on the principles and process set in motion a process of engagement working with interested parties to shape research agendas, make decisions about research focus, ensuring their voice is heard in ways they consider appropriate and controlling outcomes with a commitment to research leading to change (Mullender, Ward, Fleming, 2013, p.165, 166).

What we did find in England at least was that the involvement of social workers and probation officers in groupwork has almost evaporated over the past 20 years. In the 1990s groupwork was a core element of social work training; now very few universities in England teach it (although this is not the case around the world). As the focus of state social work has narrowed to the oversight and management of individuals and families, groupwork seems to be seen as less relevant. Another significant change was that in 1991 the role of facilitator in a group was predominantly considered the province of a professional worker (Ward and Mullender, 1991); however in 2012 we found much self-directed groupwork in the voluntary sector and many groups with no 'professional' involvement at all. There are many self-run, service user led and egalitarian groups facilitated by group members. In these groups roles are often fluid, with groupwork tasks being recognised and shared amongst members.

Groupwork Vol. 23(2), 2013, pp.xx-xx. DOI: 10.1921/4901230203 


\section{Groupwork roles}

What has become readily apparent is that the distinction between facilitators and group members was blurred in many groups. The descriptions of facilitation in Mullender and Ward (1991) and Ward and Mullender (1991) were based on the assumption that the group leader/ facilitator would be an outsider, and they would control the process that the group went through. What was distinctive at that time was that the focus and the content of the groupwork were decided by the members. However, in reality, within self-directed groupwork the groupwork tasks and facilitation functions have never been the sole province of the groupworkers, whether they are peers or outside workers?, paid or voluntary. In the model, group maintenance, for example, is shared as far as possible with all group members, and increasingly so over time. Where a facilitator does exercise such functions, this is done, not through any special privilege or superior understanding, but on behalf of the group.

It is often the case that a facilitator will require the skills to work with people who have had little or no experience of working collectively and who may need a good deal of individual support within the group early on, mediating conflict and attempting to mend relationships where trust has broken down. From a feminist perspective, Page (1983) argued that such personal, or process, aspects of work must be recognised and attended to as carefully as the rather macho-sounding issues of strategies, campaigns, tactics and action. This is encompassed in the self-directed groupwork/Social Action principle that states:

methods of working must reflect non-elitist principles: the facilitator's role is to enable people to make decisions for themselves and take ownership of whatever outcome ensues.

Everybody's contribution to this process is equally valued and we should rethink the meta-language used when talking about 'taking action' as much as the action itself, since the two are heavily intertwined. 
Facilitation and groupwork tasks in self-directed groupwork

\section{The 'outside' facilitator}

Facilitators in self-directed groups, when they are health and social care professionals from outside the group, need to base their style of intervention firmly on recognising that all members already have skills, understanding and ability. They should employ a non-patronising approach based on the belief that people already know and understand many of the issues surrounding the reality of their lives (Longres and McLeod, 1980, p.269). They also need techniques for encouraging group members to ask themselves the broader questions about the political, economic and social factors that contribute to the actual difficulties they face in their lives. Provided they can do this, health and social care professionals have a significant contribution to make:

Workers do have a certain knowledge and expertise that derives from their own experience - from training and from their involvement in practice. This expertise will be largely demonstrated in their ability to develop discussion and to be used as a source of information. It is not an expertise that requires deference from the group, but it is the special contribution made by the .... worker. (Longres and McLeod, 1980, p. 270)

That such an approach is valued by group members is illustrated by the comments made years later, by a group member of the Ainsley Teenage Action Group (one of the self-directed groups run in Nottingham in the 1980s and described in Self-Directed Groupwork), facilitated at the time by a Probation Officer, a youth worker and a university social work lecturer:

Why did we show up for two hours every week? We were in control, we were in charge. We set the guidelines. When we first started off, we thought we would do it and just not get into trouble - then it carried on, and people started to listen to us.... You were just on the sidelines. We did what we wanted to do without people being in charge. You let us get on with it basically. (group member)

Arches and Fleming (2007, pp. 40, 42)

Groupwork Vol. 23(2), 2013, pp.xx-xx. DOI: 10.1921/4901230203 
Jennie Fleming and Dave Ward

\section{Changing roles: Handing over to the group}

The self-directed groupwork model always allowed for group members taking more control as time went on. As groups progress through the stages of the model, members frequently take on more and more responsibility for the group. They increasingly share both groupwork and practical tasks with the original facilitators who may be paid workers or fellow, perhaps founding, group members. As Ward and Mullender wrote,

the involvement of workers in group maintenance will reduce over time as groups become able to take on more and more of the responsibility' (1991, p.145)

Together, everyone engages in what Longres and McLeod (1980, p.271) refer to as 'the process of discovery, development and change', whilst the facilitator encourages group members to recognise the capabilities they obviously possess. In this way, the groupworker task changes from an emphasis on structuring the decision-making process to creating space and opportunities for group members to work autonomously. Different group members come to the fore and use new found skills and confidence; there can be less reliance on key individuals who perhaps had a role in establishing the group initially, as ownership becomes more widely held and a larger number of people take responsibility for both tasks and group maintenance.

An example of this change of roles took place within a neighbourhoodbased group of young people in Nottingham. On the first occasion, when the group members ran a summer holiday activity scheme, the facilitators had to assist members in detail on all aspects of the planning and running of the scheme. The next time round, the groupworkers stayed in the background and played a more advisory role. In direct terms, they only needed to provide, or to point members towards, for example, information on sources of funding, regulations relating to play schemes and on the practicalities of running their scheme. This left members free to consolidate and extend the skills and awareness they had developed previously. This process is also visible in the Youth Dreamers, who have written in Groupwork in the past (Carey et al, 2004). Youth Dreamers is a long standing group of young people working with a teacher in Baltimore to develop a youth-run centre 
(http://www.youthdreamers.org/). As young people have become more knowledgeable about writing applications for funding, contacting potential supporters, contributing to meetings with adults and confident to facilitate after-school sessions for other young people, the role of the supporting teacher has retreated more into the background to become seen as a resource to the group (Berdan et al, 2006, p.35).

To be sensitive to these changes and to adapt their practice accordingly, facilitators need to be on their toes - using evaluation processes to stay alert to the way the group is evolving. The same questions form the framework of evaluation as those which lie at the heart of the practice itself:

- What are the issues and problems members face?

- Why do these problems exist?

- How can we as facilitators enable members to achieve change?

Of course, at any stage of the process, in order to keep the work progressing non-oppressively, these questions must be guided by and asked within the framework of the six principles which underpin all self-directed groupwork. These principles can be viewed dually, both as underpinning values but also practically, as directions for undertaking practice.

As groups develop and mature, they become able to spot and handle challenges and tasks by themselves. They become increasingly secure in the authority of their own knowledge base (Munn-Giddings and McVicar, 2007). For example, the Youth Dreamers acknowledge the different levels of support and contribution members can offer and point out it is possible for young people to be involved at a range of levels: from being members of the Board, facilitating sessions on a regular basis, taking part in one-off events and, of course, simply using the centre. Participants can move between these levels of involvement and responsibility as they gain experience and confidence.

Some of the 'seasoned' Youth Dreamers in considering a series of questions posed to them by the authors, have reflected on how the Social Action/self-directed groupwork principles can be seen in their work and how they influence the roles that Youth Dreamers take. For example, one of their responses, in their own words, says:

Groupwork Vol. 23(2), 2013, pp.xx-xx. DOI: 10.1921/4901230203 
Jennie Fleming and Dave Ward

People have choice about how they share their skills, understanding and ability: Newer youth don't have the same ownership as the original crew so the buy-in is a bit more challenging. They come into the beautiful house and have no idea how hard we worked to create it. We always include a component of peer teaching where the 'seasoned' Youth Dreamers 'teach' the 'fresh' Youth Dreamers about how we got to this point. This includes scavenger hunts through the house and our photo timeline, peer lessons in grant writing, fundraising, designing after school programs, etc.

We value people's strengths in a number of ways that include:

- We realize that not everyone has the same strengths, so we respect people's strengths and ideas.

- Volunteers help by choice, running and creating programming that utilizes their individual strengths, to teach and mentor students.

- We use creativity and groupwork to encourage and aid our children in learning and perfecting new skills.

- People have rights; rights to decision to take part, on the issues, and action; to choose; to be heard; to control the agenda.

- Since the Youth Dreamers began, decision making has been a group process where everyone has a part and opinion in decision making.

- Youth Dreamers has a board of directors, composed of eight youth and eight adults who work together to form committees to run our programming and make important financial, social, and other such decisions. This shows youth and adults working together to achieve a common goal.

- All adults work hard to facilitate the voice of youth, allowing them to take the lead with icebreakers, peer teaching, grant writing and more.

One of the Youth Dreamers who was part of the initial group of young people, writes again in response to questions from the authors, about how their Dream House is run now:

We are the pioneers of what happens in our organization. We have a team of Youth Dreamers (the Dream Team) who meet once a month to evaluate programs and seek ways to improve. Our Dream Team reflect, analyze, and evaluate each of our programs, and decide what types of fundraisers and events we want to take on. They essentially manage the nonprofit and run the center. Everyone has a voice and is encouraged to use it, even our Board of Directors in which both youth and adults serve on. We use their expertise, experience, and guidance to ensure that we are making ethical and safe choices that align with our mission, vision, and goals. 


\section{Withdrawing}

The open-ended nature of self-directed groups, means that eventually the facilitators, especially if they are professionals or from outside the group, may need to judge when it is appropriate to withdraw completely from the group. Even if they were the initiators, they do not necessarily need to continue forever. However:

Letting go of almost anything you have been instrumental in starting is not easy. When a carers' group moves from being social worker led to member run, everyone

- both members and professionals involved - needs to think through the issues ....

Professionals ... often have unreal expectations about this sort of change. They underestimate the complexity of it and the time it will take. (Wilson, 1988, p.34)

When a group is contemplating becoming self-sustaining, action and direction, like participation, may require formal and explicit structures based on democratic principles (Freeman, 1970, pp.7-8). These include delegating responsibility and distributing authority to those best able to handle it, rather than to the most popular or most dominant individuals. Various groups have chosen to rotate or share tasks amongst all members. The group itself, according to Freeman, needs to determine who will exercise power and authority and who will have access to information and, to ensure that this transition does not entail becoming oppressive in the process, to share both as widely as possible.

There is no single clear process of how power can be transferred in professionally-initiated groups to the members (Seebohm et al, 2010). It is a two-way process. As the members gain more autonomy, the groupworker too must be preparing to release control and move out of the 'central person' role (Preston-Shoot, 2007, pp.146-150). This needs to be done in a skilled and measured way, giving attention to both practical and relationship aspects of the group's functioning. Rather than a uniformly paced withdrawal, as would be the case in structured conventional groupwork, letting go involves the skill of gauging when the group has become sufficiently self-motivating and self-resourcing for the facilitators' contribution to its functioning, at both task and emotional levels, no longer to be essential. Unless the group has become 
resourced from elsewhere or has achieved its purpose and is drawing to a natural end, it is crucial for the facilitators to make a realistic assessment, in discussion with group members, of the group's strengths and functioning at the time, not arising from a pre-determined idea of what is appropriate in general terms.

This stage in a group's life needs to be viewed flexibly and there are a variety of ways that members can be supported to achieve more shared and distributed power. Strategies can include coming initially to alternate meetings, then, in consultation with members, every third meeting and so on; or at the end of each meeting, when plans are being made for 'what next', part of the discussion could be whether the facilitator needs to attend or not. In the work done at the Service Learning project in the USA, (Arches, 2012), college students develop their own skills in self-directed groupwork before going out to work with school students. The college students rotate the role of facilitator amongst themselves in university class - so developing with their peers both the skills and confidence to take on facilitation roles.

Some groups claim to be self-directed, but follow a scheduled number of weeks of facilitation. They often do not long outlive the workers leaving, thereby providing an example of two common errors made about how facilitators can reduce their role in groups. First, withdrawal is built into the planning of a group in advance and, second, that it is a 'once and for all' activity. This is often the case where groupworkers have been attracted by the efficacy of the WHAT, WHY, HOW process in beginning a group and engaging the motivation of members, but have not fully understood and adopted the statement of principles of Self-directed Groupwork out of which flow an open-ended timescale and withdrawal only by negotiation and in agreement with members. CIFAN is a group of North American public organisation workers who were unhappy about the directive and authoritarian management approaches which are being introduced into their workplace. A trade union officer found out about the self-directed groupwork process and, after a brief introduction to the approach, decided to apply it to a series of three meetings she was convening. An agenda for action was formulated at the end of the third meeting and roles and responsibilities were delegated to a small number of volunteers. Follow-up meetings were called but were poorly attended and the campaign did not gain momentum. The facilitator had viewed the self-directed approach as a 
strictly time-limited intervention, very possibly on assumptions arising from other areas of her work. Members had had an initial experience at the three meetings, which, according to all accounts, they experienced as positive and empowering but the premature termination of selfdirected facilitation had cast them adrift, and unable to build on the foundations hastily created in just 3 meetings.

Nevertheless, many groups have moved to a position in which 'professional' facilitation is minimal. One vital feature of the Youth Dreamers has been how the 'seasoned' Youth Dreamers support the integration of 'fresh' Youth Dreamers and how they work together to both keep the vision alive over a very long period of time, and also allow new ideas and developments to be incorporated. Over time the young people have come to take more and more control and responsibility for the actions of the group.

\section{Self facilitated groups}

Other groups have never sought - or have, indeed, positively rejected involvement from 'outsiders' to support them. We came across a number of examples of such groups in our recent investigations.

One self-run group that recognised the self-directed process in what they did was a local young people's group that campaigned against 'mosquito' devices (instruments which emit high pitched noise aimed at deterring young people from gathering in certain public areas) on city council properties in their city. There was a core group of about 6 or 7 young people who did most of the action and met face to face. There was also a wider group of young people with more virtual involvement, for example through email, Facebook and Twitter (about 30 of them). The core group members used facebook groups to attract interest and gauge the opinions of a very wide group of young people about the devises - all wanted a ban.

As part of their campaign they linked with national children's rights organisations and spoke with local and national politicians. When they were successful with their local campaign they developed an action plan based on detailing the work they had undertaken and made it available to other groups of young people to use if they wanted. The campaigns gained support of the Children's Commissioners in England and 
Scotland (BBC ,2011) and this specific group was used as a case study in Positive for Youth a document produced by the Parliamentary Under Secretary of State for Children and Families in the UK Department for Education (Department for Education, 2011, p.68). One of the core group members, who was familiar with Social Action principles and process, says that their group could be called a Social Action group and he could recognise both the principles and process in how they worked together and what they did, although they had not overtly set out to be a Social Action group.

Advocacy in Action is a group that positively chooses not to have professional involvement. There are no workers in Advocacy in Action but there are 'facilitators'; these can be any member and people can take different facilitating roles within the group. For example, a woman with learning difficulties facilitates a group of women who have experienced sexual abuse. They do recognise that there are tasks that need to be done to maintain a group but do not see these as the province of any particular person as everybody contributes to this. They recognise the skills of all group members and value equally the qualities people bring to the groups - for example the importance of a smile or holding a hand when people do not feel included. In their experience people are keen and ready to take on responsibility for group process and to work together in such a way that all are able to do this.

Members of Advocacy in Action feel it is important that people watch and learn from others within the group and have the opportunity to model ways of being in a group. No one has been on a course about groupwork or how to run groups - they develop the skills themselves in practice and these are then shared among group members. In like manner, they recognise that people have the right to define their own experience and within Advocacy in Action make room for people to make decisions for themselves, creating what they describe as 'growing spaces'.

Family Advocacy Network is a service user led network. Groupwork is their primary means of working. Like Advocacy in Action, it has been a conscious decision not to have a professional facilitating a group - they prefer to do it themselves. Members seek to create a safe environment which they say that they find easier to do without professional involvement. A consequence of this safe environment is that people do feel able to show their emotions - they get angry or cry because of their 
frustrations or grief. Given setbacks and disappointments that members experience in their lives, this is not surprising and it is seen as vital that people feel able to express emotions in the group, considering this to be an important feature of service user led groups.

In Family Advocacy Network roles are informal and often members just see a need and fulfil the role. They have found that supportive peer-to-peer relationships are often less predominant in professionally facilitated groups than in service user led ones. They acknowledge it is possible that facilitation might be smoother and more practiced with professional involvement but there are issues of power and control that cannot always be resolved - they say that different needs and different agendas are highlighted if professionals are involved. With professionals present they have found that some group members become very quiet and can be intimidated - they quickly stop asking questions. After all, professionals as gatekeepers are often the problem in people's lives and are not seen as potential allies:

We need to organise ourselves and offer own support, we can invite professionals in if we think it would be useful. (interview with group member)

Commonality of experience is very important for members of Family Advocacy Network. For example, one member had cared for his parents with dementia and had found he was fighting lots of 'mini-battles' to get past 'all the people who say 'No!'. He could see others struggling with precisely the same things and the group began informally with people sharing knowledge and experience, for example, of having been to a tribunal, of helping others prepare themselves or of going with them to a meeting. At the group sessions a member presents their problem or issue or particular challenge they are facing; then the other group members speak about it, drawing on their own experience to advise and offer insights. As well as achieving practical successes, recognising solidarity with others who have similar experiences can be uplifting. The discussions in the group have helped members understand that others face the same kinds of problems and obstacles as they did; they recognise the social oppression of people such as themselves but also their own potential power and ability to have greater control over their lives. Furthermore, participants have built friendship and support networks through the group which, as well as relieving isolation, have fostered awareness, self-confidence and self-esteem.

Groupwork Vol. 23(2), 2013, pp.xx-xx. DOI: 10.1921/4901230203 


\section{Conclusion}

The term 'self-directed groupwork' has always encapsulated a style of working in which facilitators do not lead the group, but facilitate people in making decisions for themselves and in controlling whatever outcome ensues. The model has always been grounded upon the recognition that the skills and knowledge of facilitation do not accord privilege or power to the facilitator, and has never considered that this role and ensuing tasks were the province only of the facilitator. Rather, they pass increasingly to group members as groups develop. What has been exciting to observe is how, since the model was first formally conceptualised in 1991, this key element has evolved further. In many groups participants have really 'taken over' and in some, indeed, they have decided, from the outset, not to designate the tasks of facilitator to any specific individual, least of all to a professional, but rather to share them amongst all group members.

\section{References}

Abels, P. and Garvin, C. (2010) Standards for Social Work Practice With Groups (2nd edition). Alexandria(VA): Association for the Advancement of Social Work with Groups

Arches, J. (2012) The role of groupwork in social action projects with youth. Groupwork, 22, 1, 59-77.

Arches, J. and Fleming, J. (2007) Building our own monument: A social action group revisited. Practice, 19, 1, 33-47

Aubrey, J. (2004) The roots of social action. Groupwork, 14, 2, 6-23

BBC (2011) Teenagers should challenge use of mosquito devices. BBC News website. [Accessed 20 December 2011 at http://www.bbc.co.uk/news/ukpolitics-16273076]

Berdan, K., Boulton, I., Eidman-Aadahl, E., Fleming, J., Gardner, L., Rogers, I. and Solomon, A. (Eds.) (2006) Writing for a Change: Boosting literacy and learning through social action. San Francisco: Jossey-Bass

Berdan, K. (2006) Reflections on the Youth Dreamers. in K. Berdan, I. Boulton, E. Eidman-Aadahl, J. Fleming, L. Gardner, I. Rogers, and A. Solomon (Eds.) (2006) Writing for a Change: Boosting literacy and learning through social action. San Francisco (CA): Jossey-Bass (pp. 31-41) 
Cary, C., Ried, C. and Berdan, K. (2004) Involving school students in social action in America: The Youth Dreamers Group. Groupwork, 14, 2, 64-79

Cohen, M. B. and Mullender, A. (2000) The personal in the political: Exploring the group work continuum from individual to social change goals. Social Work with Groups, 22, 1, pp.13-31 (Reproduced in 2005, Social Work with Groups, 28, 3/4 and simultaneously in Malekoff, A. and Kurland R. (Eds.) A Quarter Century of Classics (1978-2004): Capturing the Theory, Practice and Spirit of Social Work with Groups (pp.187-204)

Department for Education (2011) Positive for Youth: A new approach to crossgovernment policy for young people aged 13 to 19. London: Department for Education. Available at http://media.education.gov.uk/assets/files/pdf/p/ positive\%20for\%20youth.pdf]

Fleming, J. (2009) Social Action. in A. Gitterman and R. Salmon (Eds.) Encyclopedia of Social Work with Groups. New York and London: Routledge (pp.275-277)

Fleming, J. and Luczynski, Z. (1999) Men United: Fathers' voices. Groupwork, $11,2,21-38$

Fleming, J. and Ward, D. (1999) Research as empowerment: The social action approach. in W. Shera and L. Wells (Eds) Empowerment Practice: Developing richer conceptual foundations. Toronto: Canadian Scholars' Press (pp370-389)

Freeman, J. (1970) The Tyranny of Structurelessness. [Accessed at 27 October 2011 at www.jofreeman.com/joreen/tyranny.htm]

Harrison, M. and Ward, D. (1999) Values in context: Groupwork and social action. Groupwork, 11, 3, 80-103

Longres, J. and McLeod, E. (1980) Consciousness raising and social work practice. Social Casework, May, 267-276

McIntyre, A. (2008) Participatory Action Research. Thousand Oaks, CA: Sage

Mullaly, B. (2010) Challenging Oppression and Confronting Privilege. Don Mills, Ont: Oxford University Press

Mullender, A., Ward, D. and Fleming, J. (2013) Empowerment in Action: Selfdirected groupwork. Basingstoke: Palgrave Macmillan

Mullender, A. and Ward, D. (1991) Self-Directed Groupwork: Users take action for empowerment. London: Whiting and Birch

Mullender, A. and Ward, D. (1985) Towards an alternative model of social groupwork. British Journal of Social Work, 15, 155-172

Munford, R. and Walsh-Tapiata, W. (2001) Strategies for Change: Community development in Aotearoa/New Zealand. Palmerston North, NZ: School of Social Policy and Social Work

Groupwork Vol. 23(2), 2013, pp.xx-xx. DOI: 10.1921/4901230203 
Munn-Giddings, C. and McVicar, A. (2007) Self-help groups as mutual support: what do carers value? Health and Social Care in the Community, 15, 1, 26-34

Page, M. (1983) Language and community politics - or exorcising the old ideal! Talking Points, 42. London: Association of Community Workers

Preston-Shoot, M. (2007) Effective Groupwork. Basingstoke: Palgrave Macmillan Seebohm, P., Munn-Giddings, C. and Brewer, P. (2010) What's in a name? A discussion paper on the labels and location of self-organising community groups, with particular reference to mental health and Black groups. Mental Health and Social Exclusion, 14, 3, 23-29

Ward, D. and Mullender, A. (1991) Facilitation in self-directed groupwork. Groupwork, 4, 2, 141-151

Whitmore, E., Wilson, M. and Calhoun, A. (2011) Activism that Works. Black Point, Nova Scotia: Fernwood Publishing

Wilson, J. (1988) When to let go. Community Care, 26th May, pp.34-35 